\title{
Comparative structure and biomechanics of plant primary and secondary cell walls
}

\author{
Daniel J. Cosgrove ${ }^{1 *}$ and Michael C. Jarvis ${ }^{2}$ \\ 1 Department of Biology, Pennsylvania State University, University Park, PA, USA \\ 2 School of Chemistry, University of Glasgow, Glasgow, UK
}

\section{Edited by:}

Jose M. Estevez, University of Buenos Aires and Consejo Nacional de Investigaciones Científicas y

Técnicas, Argentina

Reviewed by:

Anja Geitmann, Université de Montréal, Canada

Ingo Burgert, Max Planck Institute of Colloids and Interfaces, Germany

${ }^{*}$ Correspondence:

Daniel J. Cosgrove, Department of Biology, Pennsylvania State

University, 208 Mueller Laboratory,

University Park, PA 16802, USA.

e-mail:dcosgrove@psu.edu
Recent insights into the physical biology of plant cell walls are reviewed, summarizing the essential differences between primary and secondary cell walls and identifying crucial gaps in our knowledge of their structure and biomechanics. Unexpected parallels are identified between the mechanism of expansion of primary cell walls during growth and the mechanisms by which hydrated wood deforms under external tension. There is a particular need to revise current "cartoons" of plant cell walls to be more consistent with data from diverse approaches and to go beyond summarizing limited aspects of cell walls, serving instead as guides for future experiments and for the application of new techniques.

\section{Keywords: cellulose, creep, deformation, growth, primary cell walls, secondary cell walls, xyloglucan}

\section{INTRODUCTION}

Primary and secondary cell walls are microfibril-based nanocomposites that differ in the arrangement, mobility and structure of matrix polymers, the higher-order organization of microfibrils into bundles and discrete lamellae, their rheological and mechanical properties, and their roles in the life of the plant. Wall structure has sometimes been compared with that of fiberglass - a plastic matrix reinforced by glass-fibers - but this analogy fails to account for the complex rheological behavior of plant walls. In this mini-review we summarize recent insights linking the molecular organization of cell walls with their mechanical and rheological properties.

Primary cell walls are synthesized during growth and typically are relatively thin, pliant, highly hydrated structures. The primary wall must be strong to withstand the tensile forces arising from turgor pressure, extensible to allow wall stress relaxation which motivates cell water uptake and physical enlargement of the cell (Hamant and Traas, 2010), and incorporative, meaning capable of linking newly deposited wall polymers into the load-bearing structure. These properties partly derive from the physical structure of the wall, but they also involve dynamic actions by expansin and xyloglucan endotransglycosylase/hydrolase (Cosgrove, 2005; Eklof and Brumer, 2010).

Secondary cell walls provide strength and rigidity in plant tissues that have ceased growing. Any tall terrestrial plant requires stems with bending strength and with water-conducting tissues that can withstand negative pressures (Koch et al., 2004; Speck and Burgert, 2011). Secondary walls therefore need compressive as well as tensile strength, but not extensibility. Nevertheless, under some conditions they can undergo various deformation processes that resemble, to some degree, primary cell wall growth.

\section{STRUCTURE AND BIOMECHANICS OF GROWING WALLS}

Primary walls are comprised of $15-40 \%$ cellulose, $30-50 \%$ pectic polysaccharides, and $20-30 \%$ xyloglucans and lesser amounts of arabinoxylans and structural proteins, on a dry weight basis, structured into one or more lamellae. The pectic polysaccharides are particularly important for wall hydration, which is essential for the slippage and separation of cellulose microfibrils during expansive growth. Notable deviations from this generic composition include the primary walls of:

- grasses, where arabinoxylans constitute most of the matrix; mixed-linkage glucans transiently comprise $10-20 \%$ of wall mass (Carpita et al., 2001; Gibeaut et al., 2005);

- celery and sugar beet parenchyma, which are rich in cellulose and pectin, but have little hemicellulose (Thimm et al., 2002; Zykwinska et al., 2007b).

Understanding how mechanical performance emerges from molecular structure - particularly the mechanism of cell wall expansion - has been a key raison d'être of primary cell wall models for decades (Keegstra et al., 1973; Preston, 1974; Cosgrove, 2005), yet despite significant progress we still have a long way to go to achieve the "consistency of molecular structure with the physical properties of the walls during growth" (Carpita and Gibeaut, 1993).

Studies of the viscoelastic properties of primary walls - summarized in numerous reviews (Preston, 1974; Cosgrove, 1993; Geitmann, 2010) - show that unaided viscoelastic extension of walls decays rapidly, amounting to a few \% extension, whereas in the living plant it continues for hours or days and results in extensions of $50-100 \%$ or more. Normal cell wall expansion is not a simple result of the wall's constitutive properties but results from continuous action by the cell or by wall-associated proteins. 
It follows that measures of wall viscoelasticity may correlate with wall structure at any given instant, but these physical measures generally do not encompass this active aspect of wall extensibility, which has sometimes been described as chemorheological creep, meaning polymer creep that depends on chemical or enzymatic modification (Ray and Ruesink, 1962). The gap between in vitro and in vivo extensibility is at least partly filled by the action of expansins, which induce stress relaxation and sustained creep of cell walls (Sampedro and Cosgrove, 2005). Although we know expansin structure in atomistic detail (Yennawar et al., 2006), the details of its loosening action on the wall remain enigmatic, in part because our understanding of the molecular architecture of the primary wall is incomplete.

\section{CONVENTIONAL VIEW OF XYLOGLUCAN'S ROLE IN WALL MECHANICS}

According to current depictions of primary walls, cellulose microfibrils are coated by xyloglucans and tethered by them to form a load-bearing network, with pectins functioning as a co-extensive, space-filling matrix that separates the microfibrils. This "tethered network model" (Figure 1A) might exhibit turgor-driven yield and creep resembling real primary cell walls if xyloglucan binding was dynamic and reversible (Veytsman and Cosgrove, 1998; Dyson and Jensen, 2010). However, if xyloglucan bound cellulose tightly and irreversibly, as appears to be true, this network would behave more like a viscoelastic solid, with retarded elasticity due to the time needed for unfolding of xyloglucan tethers and viscous movement of the cellulose microfibrils within the pectic matrix (Abasolo et al., 2009). On the other hand, there is some doubt that xyloglucan-cellulose binding has sufficient strength to withstand the tensile forces in the wall (Thompson, 2005). This issue seems an open question that might be addressed by molecular dynamics simulations (Bergenstrahle et al., 2009). A thorough analysis is complicated by microfibril structure which has distinct hydrophobic and hydrophilic surfaces as well as disordered regions, which likely differ in xyloglucan binding. Furthermore, xyloglucan may be entrapped within microfibrils or bundles of microfibrils, further complicating such analysis.

The elastic behavior of a multi-lamellate version of the tethered network has been modeled by a finite-element simulation, absent the pectin component (Kha et al., 2010). A key advantage of this approach is that the spatial distribution and range of tensile loads can be calculated for individual tethers. This may be important for extending the model to incorporate viscoelastic extension and creep behavior of walls in a realistic way.

Using another approach, Dyson etal. (2012) modeled the effects of stretch-dependent cross-link breakage on cell wallyielding behavior, incorporating potential effects of expansin and xyloglucan endotransglycosylase/endohydrolase. The results resemble Lockhart's semi-empirical equation in which the rate of wall expansion is given by $\varphi(P-Y)$, that is, extensibility $\varphi$ times turgor pressure $P$ in excess of the yield threshold $Y$ (Lockhart, 1965). Moreover, the model offers a molecular interpretation of $\varphi$ as due to the pectin viscosity and $Y$ as related to the density of xyloglucan tethers. These are testable predictions.

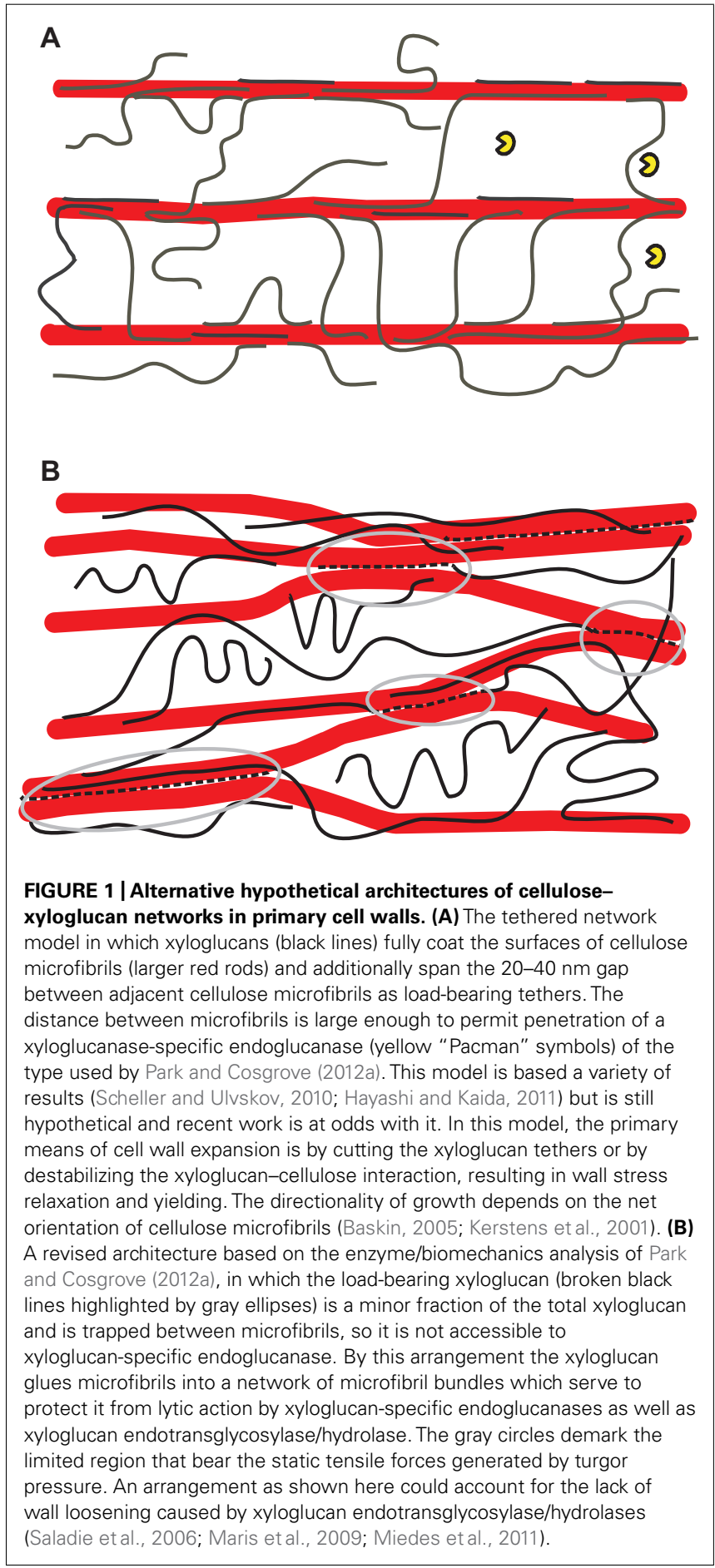

\section{GROWING DOUBTS ABOUT XYLOGLUCAN'S ROLE}

Despite the widespread acceptance of the tethered network model, recent results have led to some doubts about its correctness. As mentioned above, some walls contain little hemicellulose. Attempts to measure xyloglucan bound to cellulose by ${ }^{13} \mathrm{C}-\mathrm{NMR}$ in intact Arabidopsis and mung bean walls concluded that $<10 \%$ of the cellulose surface is coated with xyloglucan, contrary to expectations of the dominant model (Bootten et al., 2004; Dick-Perez 
et al., 2011). Much of the xyloglucan interacted with pectins, which showed extensive interactions with cellulose. Neutral pectins bind to cellulose in vitro, although less avidly than does xyloglucan (Zykwinska et al., 2007a, 2008).

Another blow to the tethered network model came from analysis of mutants defective in xyloglucan synthesis which displayed only modest growth defects despite the complete absence of xyloglucan (Cavalier et al., 2008; Zabotina et al., 2012). Further analysis showed that pectins and xylans assumed greater biomechanical roles in the xyloglucan-deficient walls (Park and Cosgrove, 2012b) which were mechanically weaker but simultaneously less extensible because they lacked the major target of $\alpha$-expansin. Xyloglucan may also affect microfibril structure or aggregation (Atalla et al., 1993), with indirect consequences for the effectiveness of wall-loosening agents. This idea draws some support from NMR analyses (Dick-Perez et al., 2011) and confocal microscopy (Anderson et al., 2010) which indicate that the xyloglucan-deficient walls contain larger cellulose microfibrils or microfibril bundles compared with wildtype walls.

A revised view of xyloglucan's role recently emerged from experiments in which substrate-specific endoglucanases were assessed for their ability to induce wall creep (Park and Cosgrove, 2012a). Although xyloglucan-specific endoglucanases removed much of the xyloglucan, they did not increase wall creep or compliance. Cellulose-specific endoglucanases were likewise inactive in biomechanical assays. Only enzymes able to hydrolyze both xyloglucan and cellulose were active in these assays, with large biomechanical effects associated with digestion of $\sim 0.3 \%$ of the total xyloglucan. These results argue against the tether model (Figure 1A), as such tethers would be digested by xyloglucanspecific enzymes. Figure 1B shows one possible scheme consistent with the new results, where the biomechanically significant xyloglucan is restricted to inaccessible junctions between microfibrils.

These studies de-emphasize the role of xyloglucan as the exclusive moderator of cell wall mechanics and indicate that other matrix polysaccharides may fill in for some xyloglucan functions. This idea is further reinforced by studies showing pectin de-esterification is linked with enhanced growth in the Arabidopsis hypocotyl (Pelletier et al., 2010) and in the outgrowth of leaf and flower primordia in the shoot apical meristem (Peaucelle et al., 2008, 2011). These effects of pectin methyl esterase are hard to understand in terms of wall structure because pectin deesterification, by itself, should lead to enhanced ionic cross linking of pectins, thereby rigidifying the wall (Zhao et al., 2008). Indirect effects of pectin de-esterification may be linked to these growth enhancements (Wolf and Greiner, 2012). Moreover, pectin may play a greater role in specialized walls found in pollen tubes and in some algae (Fayant et al., 2010; Rojas et al., 2011; Palin and Geitmann, 2012).

\section{BIOMECHANICS OF SECONDARY CELL WALLS}

In most angiosperms the functions of water conduction and support are divided between vessels and interfascicular xylem cells, patterned through the influence of distinct transcription factors (Guo et al., 2009; Ohtani et al., 2011) and intercellular signaling networks (Fuchs et al., 2011). The requirement for tensile and compressive strength is satisfied by a high content of rather uniformly oriented cellulose, synthesized by a distinct set of cellulose synthases and normally lignified. In trees the result is wood (Mellerowicz and Sundberg, 2008). Xylem tissues broadly similar in structure and function, although often with less lignin or none (Carlquist and Schneider, 1998; Hepworth et al., 1998; Jung and Engels, 2002) are found in herbaceous plants, bamboos, and palms.

Like primary cell walls, secondary cell walls are composite materials based on 3-nm cellulose microfibrils, with lignin, xylans, and glucomannans replacing xyloglucans and pectins (Mellerowicz and Sundberg, 2008). Secondary cell walls are less hydrated than primary cell walls, containing only about $30 \%$ water at saturation. In coniferous wood at least, the cellulose microfibrils form loose bundles 10-20 nm across with direct lateral adhesion between adjacent microfibrils over part of their length (Fernandes et al., 2011). Most of the lignin and hemicelluloses are thought to lie outside these aggregates (Salmen, 2004; Fernandes et al., 2011), but hemicellulosic glucomannans are closely associated with cellulose (Salmen and Bergstrom, 2009; Figure 2). In contrast to the dispersed cellulose orientations in primary cell walls, the cellulose microfibrils are wound around wood cells in a helix whose pitch is defined by the microfibril angle, the angle that the microfibrils make with the cell axis (Barnett and Bonham, 2004). Tree saplings have high microfibril angles giving flexibility in response to wind and snow, while mature trees have low microfibril angles providing the stiffness to avoid buckling under the compressive loads imposed by their weight (Altaner and Jarvis, 2008). A tree's mechanical history is recorded in the variation of microfibril angle across the annual rings of the trunk.

Because of the importance of wood as a construction material its mechanical properties have been studied much more intensively than those of growing plant cells (Salmen, 2004). Models and tentative mechanisms have been suggested for three kinds of deformation: (1) viscoelastic (reversible) deformation; (2) an irreversible time-dependent form of deformation termed here "viscoplastic" (Flores et al., 2011); (3) mechano-sorptive deformation. Only (2) and (3) are irreversible and therefore directly analogous to the growth of primary cell walls, but it is not clear to what extent (1)-(3) are mechanistically related. All three may therefore suggest insights or potential experimental approaches that might help to understand the physical processes occurring when primary cell walls elongate.

\section{VISCOELASTIC STRETCHING AND BENDING}

Dry secondary cell walls with small microfibril angles show purely viscoelastic behavior, either in tensile or bending experiments at constant stress or by stress relaxation. The viscous component increases with the angle between the microfibrils and the stress (Bonfield et al., 1996; Gril et al., 2004) and has been modeled as due to viscous shear in the lignin-hemicellulose matrix between elastic microfibrils (Engelund and Svensson, 2011) or microfibril aggregates. The calculated free energy of activation was consistent with the breaking of four to six hydrogen bonds in each sliding event (Bonfield et al., 1996). Chemical delignification (Kohler and Spatz, 2002) or down regulation of lignin synthesis (Koehler and Telewski, 2006) generally reduced stiffness, 


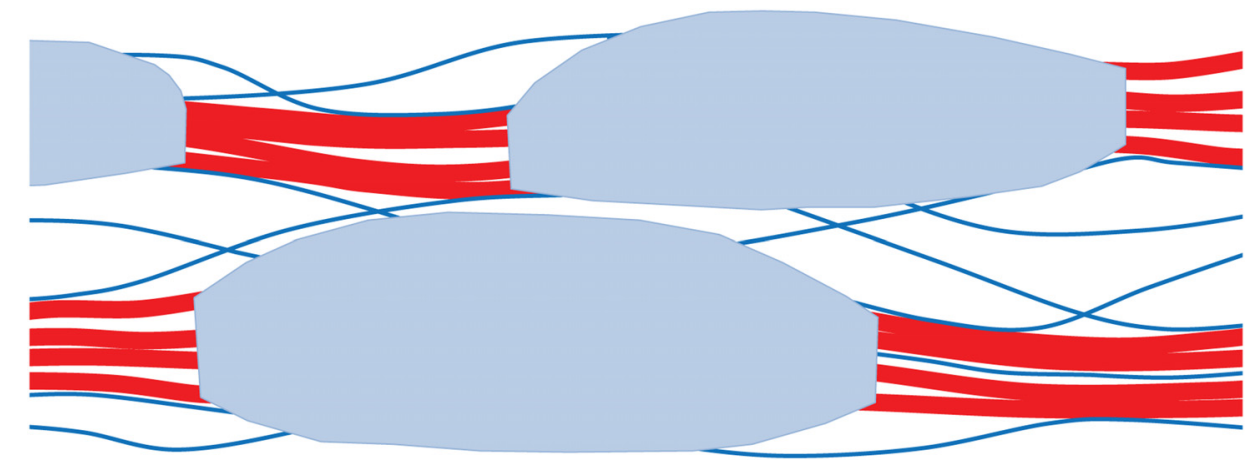

FIGURE 2 | Hypothetical architecture of polymer network in secondary cell walls of conifer wood. Loosely aggregated bundles of cellulose microfibrils (red) are coated with a disordered xylan-lignin complex (shaded light blue). Partially oriented glucomannan chains (blue lines) adhere by hydrogen bonding to the cellulose aggregates and acetylated segments of these glucomannans bridge between the aggregates. For clarity the structure is shown much more open than is the case: the free space, filled by water in vivo, is only about $40 \%$ of the total volume. This is much less than the free space in hydrated primary cell walls. Based on Terashima et al. (2009) and Fernandes etal. (2011). demonstrating involvement of lignin. There was also less direct evidence for involvement of hemicelluloses (Assor et al., 2009; Bjurhager et al., 2010), but mechanisms remain unclear at the molecular level.

\section{VISCOPLASTIC DEFORMATION ABOVE THE YIELD THRESHOLD}

When fully hydrated as in the living tree, wood with high microfibril angle shows a two-phase load-deformation curve. Above a threshold stress it becomes less stiff. This second phase of elongation is irreversible but this does not result from overt damage, because when the stress is reduced below the yield threshold the elongated sample remains as stiff as before (Kohler and Spatz, 2002; Keckes et al., 2003). Mechanically, then, elongation of wood above the yield threshold resembles turgor-driven extension growth as described by the Lockhart equation. The term "molecular Velcro" was coined to describe this form of deformation in wood because it is simulated by hook-and-loop fasteners that can be pulled apart, moved and refastened without permanent loss of strength (Keckes et al., 2003). Molecular Velcro tensile behavior has been demonstrated for wet wood samples in which the cellulose microfibrils are oriented at $20-45^{\circ}$ to the cell axis. If the wood is dry or the microfibril angle is low, the yield threshold rises until the sample breaks before reaching it (Kamiyama et al., 2005). Because of this technical problem it is common to use isolated single wood cells, which can be stretched to greater elongation than bulk wood samples without breaking (Keckes et al., 2003). The helical arrangement of the microfibrils tends to untwist on stretching, so single wood cells need to be rotationally restrained to match their behavior in wood, where each cell is locked to the next and cannot twist (Fratzl et al., 2004).

The molecular Velcro phenomenon requires that cellulose microfibrils should slide past one another and should also rotate closer to the line of stress (Flores et al., 2011): these two deformations must be balanced if the cell is not to twist (Fratzl et al., 2004). The yield threshold then corresponds to the abrupt onset of sliding between aggregates of microfibrils. Several mechanisms have been suggested to trigger this sliding process. The original suggestion was that hemicelluloses anchored to two adjacent microfibrils were entangled and that a threshold shear stress was required to break the entanglement, allowing the microfibrils to slide (Keckes et al., 2003). There is doubt about whether the orientation of hemicelluloses is consistent with entanglement interactions (Salmen and Bergstrom, 2009), and a more recent explanation of this mechanism (Speck and Burgert, 2011) substitutes lateral association of two hemicellulose chains, stabilized by hydrogen bonding over a number of residues. A further alternative mechanism involves the peeling of a hemicellulose chain off the microfibril surface by the component of the stress perpendicular to the microfibril aggregates, allowing them to slide parallel to one another until contact is restored (Altaner and Jarvis, 2008). All these triggering mechanisms focus on hemicelluloses and assume topologies rather like the "tethered network" model for primary walls, but there is evidence for the involvement of lignin as well (Kohler and Spatz, 2002) as for viscoelastic extension below the yield stress.

\section{HYGROMECHANICAL DEFORMATION}

Wood deforms progressively when maintained under a constant, often quite small, tensile or bending load through repeated cycles of drying and wetting (Bengtsson, 2001; Entwistle and Zadoroshnyj, 2008). The cumulative deformation is largely permanent unless the load is reversed. In that respect hygromechanical creep resembles viscoplastic deformation above the yield threshold, and it has been suggested to require breaking of hydrogen bonds between hemicelluloses and cellulose under hydrated conditions and their re-formation, in different locations, on drying (Entwistle and Zadoroshnyj, 2008).

All three of these forms of deformation of wood seem to be focused in the matrix region between microfibrils or microfibril aggregates, and increase simultaneously in magnitude with microfibril angle (Bengtsson, 2001; Fratzl et al., 2004; Gril et al., 2004), but it does not follow that they share exactly the same mechanism. There is an interesting parallel with the unexplained observation that stress relaxation parameters for the stretching of primary walls often correlate with growth (Nakamura et al., 2002). 


\section{CONCLUSION}

Although primary walls of growing cells possess inherent viscoelastic-viscoplastic properties arising from the polymeric nature of their structure, cell wall expansion is primarily a dynamic process requiring the action of expansins or other wall-loosening agents. Deformation of wood is considered to be physical. Nevertheless there are similarities. Both processes are sensitive to microfibril orientation and both involve interactions of hydrated non-cellulosic polysaccharides with cellulose surfaces. The topology of these interactions in response to the local distribution of

\section{REFERENCES}

Abasolo, W., Eder, M., Yamauchi, K., Obel, N., Reinecke, A., Neumetzler, L., Dunlop, J. W., Mouille, G., Pauly, M., Hofte, H., and Burgert, I. (2009). Pectin may hinder the unfolding of xyloglucan chains during cell deformation: implications of the mechanical performance of Arabidopsis hypocotyls with pectin alterations. Mol. Plant 2, 990-999.

Altaner, C. M., and Jarvis, M. C. (2008). Modelling polymer interactions of the "molecular Velcro" type in wood under mechanical stress. J. Theor. Biol. 253, 434-445.

Anderson, C. T., Carroll, A., Akhmetova, L., and Somerville, C. (2010). Real-time imaging of cellulose reorientation during cell wall expansion in Arabidopsis roots. Plant Physiol. 152, 787-796.

Assor, C., Placet, V., Chabbert, B., Habrant, A., Lapierre, C., Pollet, B., and Perre, P. (2009). Concomitant changes in viscoelastic properties and amorphous polymers during the hydrothermal treatment of hardwood and softwood. J. Agric. Food Chem. 57, 6830-6837.

Atalla, R. H., Hackney, J. M., Uhlin, I., and Thompson, N. S. (1993). Hemicelluloses as structure regulators in the aggregation of native cellulose. Int. J. Biol. Macromol. 15, 109-112.

Barnett, J. R., and Bonham, V. A. (2004). Cellulose microfibril angle in the cell wall of wood fibres. Biol. Rev. 79, 461-472.

Baskin, T. I. (2005). Anisotropic expansion of the plant cell wall. Annu. Rev. Cell Dev. Biol. 21, 203-222.

Bengtsson, C. (2001). Mechanosorptive bending creep of timber influence of material parameters. Holz Roh Werkst. 59, 229-236.

Bergenstrahle, M., Thormann, E., Nordgren, N., and Berglund, L. A. (2009). Force pulling of single cellulose chains at the crystalline celluloseliquid interface: a molecular dynamics study. Langmuir 25, 4635-4642.

Bjurhager, I., Olsson, A. M., Zhang, B., Gerber, L., Kumar, M.,
Berglund, L. A., Burgert, I., Sundberg, B., and Salmen, L. (2010). Ultrastructure and mechanical properties of Populus wood with reduced lignin content caused by transgenic down-regulation of cinnamate 4-hydroxylase. Biomacromolecules 11, 2359-2365.

Bonfield, P. W., Mundy, J., Robson, D. J., and Dinwoodie, J. M. (1996). The modelling of time-dependant deformation in wood using chemical kinetics. Wood Sci. Technol. 30, 105-115.

Bootten, T. J., Harris, P. J., Melton, L. D., and Newman, R. H. (2004). Solidstate 13C-NMR spectroscopy shows that the xyloglucans in the primary cell walls of mung bean (Vigna radiata L.) occur in different domains: a new model for xyloglucan-cellulose interactions in the cell wall. J. Exp. Bot. 55, 571-583.

Carlquist, S., and Schneider, E. L. (1998). Origin and nature of vessels in monocotyledons. 5. Araceae subfamily Colocasioideae. Bot. J. Linn. Soc. 128, 71-86.

Carpita, N. C., Defernez, M., Findlay, K., Wells, B., Shoue, D. A., Catchpole, G., Wilson, R. H., and McCann, M. C. (2001). Cell wall architecture of the elongating maize coleoptile. Plant Physiol. 127, 551-565.

Carpita, N. C., and Gibeaut, D. M. (1993). Structural models of primary cell walls in flowering plants: consistency of molecular structure with the physical properties of the walls during growth. Plant J. 3, 1-30.

Cavalier, D. M., Lerouxel, O., Neumetzler, L., Yamauchi, K., Reinecke, A., Freshour, G., Zabotina, O. A., Hahn, M. G., Burgert, I., Pauly, M., Raikhel, N. V., and Keegstra, K. (2008). Disrupting two Arabidopsis thaliana xylosyltransferase genes results in plants deficient in xyloglucan, a major primary cell wall component. Plant Cell 20, 1519-1537.

Cosgrove, D. J. (1993). Wall extensibility: its nature, measurement, and relationship to plant cell growth. New Phytol. 124, 1-23.

stresses - details best conveyed in cartoons like Figure $\mathbf{1}$ - are only now starting to be understood. In secondary cell walls the key structural elements are not individual microfibrils but bundles of microfibrils, and the possibility that this is also true in primary cell walls deserves to be explored. The research communities working on primary and secondary cell walls are rather separate, but both could benefit from converging and exchanging ideas.

\section{ACKNOWLEDGMENT}

\section{Supported by US-DOE-BES-EFRC Award DE-SC0001090.}

Cosgrove, D. J. (2005). Growth of the plant cell wall. Nat. Rev. Mol. Cell Biol. 6, 850-861.

Dick-Perez, M., Zhang, Y., Hayes, J., Salazar, A., Zabotina, O. A., and Hong, M. (2011). Structure and interactions of plant cell-wall polysaccharides by two- and threedimensional magic-angle-spinning solid-state NMR. Biochemistry 50, 989-1000.

Dyson, R. J., Band, L. R., and Jensen, O. E. (2012). A model of crosslink kinetics in the expanding plant cell wall: yield stress and enzyme action. J. Theor. Biol. 307C, 125-136.

Dyson, R. J., and Jensen, O. E. (2010). A fibre-reinforced fluid model of anisotropic plant cell growth. J. Fluid Mech. 655, 472-503.

Eklof, J. M., and Brumer, H. (2010). The XTH gene family: an update on enzyme structure, function, and phylogeny in xyloglucan remodeling. Plant Physiol. 153, 456-466.

Engelund, E. T., and Svensson, S. (2011). Modelling time-dependent mechanical behaviour of softwood using deformation kinetics. Holzforschung 65, 231-237.

Entwistle, K. M., and Zadoroshnyj, A. (2008). The recovery of mechanosorptive creep strains. J. Mater. Sci. 43, 967-973.

Fayant, P., Girlanda, O., Chebli, Y., Aubin, C.-E., Villemure, I., and Geitmann, A. (2010). Finite element model of polar growth in pollen tubes. Plant Cell 22, 2579-2593.

Fernandes, A. N., Thomas, L. H., Altaner, C. M., Callow, P., Forsyth, V. T., Apperley, D. C., Kennedy, C. J., and Jarvis, M. C. (2011). Nanostructure of cellulose microfibrils in spruce wood. Proc. Natl. Acad. Sci. U.S.A. 108, E1195-E1203.

Flores, E. I. S., Neto, E. A. D., and Pearce, C. (2011). A large strain computational multi-scale model for the dissipative behaviour of wood cell-wall. Comput. Mater. Sci. 50, 1202-1211.

Fratzl, P., Burgert, I., and Keckes, J. (2004). Mechanical model for the deformation of the wood cell wall. $Z$. Metallkd. 95, 579-584.
Fuchs, M., Van Bel, A. J. E., and Ehlers, K. (2011). Do symplasmic networks in cambial zones correspond with secondary growth patterns? Protoplasma 248, 141-151.

Geitmann, A. (2010). Mechanical modeling and structural analysis of the primary plant cell wall. Curr. Opin. Plant Biol. 13, 693-699.

Gibeaut, D. M., Pauly, M., Bacic, A., and Fincher, G. B. (2005). Changes in cell wall polysaccharides in developing barley (Hordeum vulgare) coleoptiles. Planta 221, 729-738.

Gril, J., Hunt, D., and Thibaut, B. (2004). Using wood creep data to discuss the contribution of cell-wall reinforcing material. C. R. Biol. 327 , 881-888.

Guo, Y., Qin, G. J., Gu, H. Y., and Qu, L. J. (2009). Dof5.6/HCA2, a Dof transcription factor gene, regulates interfascicular cambium formation and vascular tissue development in Arabidopsis. Plant Cell 21, 3518 3534.

Hamant, O., and Traas, J. (2010). The mechanics behind plant development. New Phytol. 185, 369-385.

Hayashi, T., and Kaida, R. (2011). Functions of xyloglucan in plant cells. Mol. Plant 4, 17-24.

Hepworth, D. G., Vincent, J. F. V., and Schuch, W. (1998). Using viscoelastic properties of the woody tissue from tobacco plants (Nicotiana tabacum) to comment on the molecular structure of cell walls. Ann. Bot. 81, 729-734.

Jung, H. G., and Engels, F. M. (2002). Alfalfa stem tissues: cell wall deposition, composition, and degradability. Crop Sci. 42, 524-534.

Kamiyama, T., Suzuki, H., and Sugiyama, J. (2005). Studies of the structural change during deformation in Cryptomeria japonica by timeresolved synchrotron small-angle X-ray scattering. J. Struct. Biol. 151, $1-11$.

Keckes, J., Burgert, I., Fruhmann, K., Muller, M., Kolln, K., Hamilton, M., Burghammer, M., Roth, S. V., StanzlTschegg, S., and Fratzl, P. (2003). Cell-wall recovery after irreversible 
deformation of wood. Nat. Mater. 2, 810-814.

Keegstra, K., Talmadge, K. W., Bauer, W. D., and Albersheim, P. (1973). The structure of plant cell walls. III. A model of the walls of suspensioncultured sycamore cells based on the interconnections of the macromolecular components. Plant Physiol. 51, 188-196.

Kerstens, S., Decraemer, W. F., and Verbelen, J.-P. (2001). Cell walls at the plant surface behave mechanically like fiber-reinforced composite materials. Plant Physiol. 127, 381-385.

Kha, H., Tuble, S. C., Kalyanasundaram, S., and Williamson, R. E. (2010). WallGen, software to construct layered cellulose-hemicellulose networks and predict their small deformation mechanics. Plant Physiol. 152, 774-786.

Koch, G. W., Sillett, S. C., Jennings, G. M., and Davis, S. D. (2004). The limits to tree height. Nature 428, 851-854.

Koehler, L., and Telewski, F. W. (2006). Biomechanics and transgenic wood. Am. J. Bot. 93, 1433-1438.

Kohler, L., and Spatz, H. C. (2002). Micromechanics of plant tissues beyond the linear-elastic range. Planta 215, 33-40.

Lockhart, J. A. (1965). An analysis of irreversible plant cell elongation. J. Theor. Biol. 8, 264-275.

Maris, A., Suslov, D., Fry, S. C., Verbelen, J. P., and Vissenberg, K. (2009). Enzymic characterization of two recombinant xyloglucan endotransglucosylase/hydrolase (XTH) proteins of Arabidopsis and their effect on root growth and cell wall extension. J. Exp. Bot. 60, 3959-3972.

Mellerowicz, E. J., and Sundberg, B. (2008). Wood cell walls: biosynthesis, developmental dynamics and their implications for wood properties. Curr. Opin. Plant Biol. 11, 293-300.

Miedes, E., Zarra, I., Hoson, T., Herbers, K., Sonnewald, U., and Lorences, E. P. (2011). Xyloglucan endotransglucosylase and cell wall extensibility. $J$. Plant Physiol. 168, 196-203.

Nakamura, Y., Wakabayashi, K., Kamisaka, S., and Hoson, T. (2002). Effects of temperature on the cell wall and osmotic properties in dark-grown rice and azuki bean seedlings. J. Plant Res. 115, 455-461.

Ohtani, M., Nishikubo, N., Xu, B., Yamaguchi, M., Mitsuda, N., Goue, N., Shi, F., Ohme-Takagi, M., and Demura, T. (2011). A NAC domain protein family contributing to the regulation of wood formation in poplar. Plant J. 67, 499-512.

Palin, R., and Geitmann, A. (2012). The role of pectin in plant morphogenesis. Biosystems. doi: 10.1016/ j.biosystems.2012.04.006 [Epub ahead of print].

Park, Y. B., and Cosgrove, D. J. (2012a). A revised architecture of primary cell walls based on biomechanical changes induced by substrate-specific endoglucanases. Plant Physiol. 158, 1933-1943.

Park, Y. B., and Cosgrove, D. J. (2012b). Changes in cell wall biomechanical properties in the xyloglucandeficient $x x t 1 / x x t 2$ mutant of Arabidopsis. Plant Physiol. 158, 465-475.

Peaucelle, A., Braybrook, S. A., Le Guillou, L., Bron, E., Kuhlemeier, C., and Hofte, H. (2011). Pectin-induced changes in cell wall mechanics underlie organ initiation in Arabidopsis. Curr. Biol. 21, 1720-1726.

Peaucelle, A., Louvet, R., Johansen, J. N., Hofte, H., Laufs, P., Pelloux, J., and Mouille, G. (2008). Arabidopsis phyllotaxis is controlled by the methyl-esterification status of cellwall pectins. Curr. Biol. 18, 19431948.

Pelletier, S., Van Orden, J., Wolf, S., Vissenberg, K., Delacourt, J., Ndong, Y. A., Pelloux, J., Bischoff, V., Urbain, A., Mouille, G., Lemonnier, G., Renou, J. P., and Hofte, H. (2010). A role for pectin de-methylesterification in a developmentally regulated growth acceleration in dark-grown Arabidopsis hypocotyls. New Phytol. 188, 726-739.

Preston, R. D. (1974). The Physical Biology of Plant Cell Walls. London: Chapman \& Hall.

Ray, P. M., and Ruesink, A. W. (1962). Kinetic experiments on the nature of the growth mechanism in oat coleoptile cells. Dev. Biol. 4, 377-397.

Rojas, E. R., Hotton, S., and Dumais, J. (2011). Chemically mediated mechanical expansion of the pollen tube cell wall. Biophys. J. 101, 1844-1853.
Saladie, M., Rose, J. K., Cosgrove, D. J., and Catala, C. (2006). Characterization of a new xyloglucan endotransglucosylase/hydrolase (XTH) from ripening tomato fruit and implications for the diverse modes of enzymic action. Plant J. 47, 282-295.

Salmen, L. (2004). Micromechanical understanding of the cell-wall structure. C. R. Biol. 327, 873-880.

Salmen, L., and Bergstrom, E. (2009). Cellulose structural arrangement in relation to spectral changes in tensile loading FTIR. Cellulose 16, 975-982.

Sampedro, J., and Cosgrove, D. J. (2005). The expansin superfamily. Genome Biol. 6, 242.

Scheller, H. V., and Ulvskov, P. (2010). Hemicelluloses. Annu. Rev. Plant Biol. 61, 263-289.

Speck, T., and Burgert, I. (2011) Plant stems: functional design and mechanics. Annu. Rev. Mater. Res. 41, 169-193.

Terashima, N., Kitano, K., Kojima, M., Yoshida, M., Yamamoto, H., and Westermark, U. (2009). Nanostructural assembly of cellulose, hemicellulose, and lignin in the middle layer of secondary wall of ginkgo tracheid. J. Wood Sci. 55, 409-416.

Thimm, J. C., Burritt, D. J., Sims, I. M. Newman, R. H., Ducker, W. A., and Melton, L. D. (2002). Celery (Apium graveolens) parenchyma cell walls: cell walls with minimal xyloglucan. Physiol. Plant. 116, 164-171.

Thompson, D. S. (2005). How do cell walls regulate plant growth? J. Exp. Bot. 56, 2275-2285.

Veytsman, B. A., and Cosgrove, D. J. (1998). A model of cell wall expansion based on thermodynamics of polymer networks. Biophys. J. 75 , 2240-2250.

Wolf, S., and Greiner, S. (2012). Growth control by cell wall pectins. Protoplasma 249(Suppl. 2), 169-175.

Yennawar, N. H., Li, L. C., Dudzinski, D. M., Tabuchi, A., and Cosgrove, D. J. (2006). Crystal structure and activities of EXPB1 (Zea m 1), a $\beta$ expansin and group-1 pollen allergen from maize. Proc. Natl. Acad. Sci. U.S.A. 103, 14664-14671.

Zabotina, O. A., Avci, U., Cavalier, D., Pattathil, S., Chou, Y. H., Eberhard, S., Danhof, L., Keegstra, K., and Hahn, M. G. (2012). Mutations in multiple XXT genes of Arabidopsis reveal the complexity of xyloglucan biosynthesis. Plant Physiol. 159, 1367-1348.

Zhao, Q., Yuan, S., Wang, X., Zhang, Y., Zhu, H., and Lu, C. (2008). Restoration of mature etiolated cucumber hypocotyl cell wall susceptibility to expansin by pretreatment with fungal pectinases and EGTA in vitro. Plant Physiol. 147, 1874-1885.

Zykwinska, A., Gaillard, C., Buleon, A., Pontoire, B., Garnier, C., Thibault, J. F., and Ralet, M. C. (2007a). Assessment of in vitro binding of isolated pectic domains to cellulose by adsorption isotherms, electron microscopy, and X-ray diffraction methods. Biomacromolecules 8 , 223-232.

Zykwinska, A., Thibault, J. F., and Ralet, M. C. (2007b). Organization of pectic arabinan and galactan side chains in association with cellulose microfibrils in primary cell walls and related models envisaged. J. Exp. Bot. 58, 1795-1802.

Zykwinska, A., Thibault, J. F., and Ralet, M. C. (2008). Competitive binding of pectin and xyloglucan with primary cell wall cellulose. Carbohydr. Polym. 74, 957-961.

Conflict of Interest Statement: The authors declare that the research was conducted in the absence of any commercial or financial relationships that could be construed as a potential conflict of interest.

Received: 02 July 2012; accepted: 13 August 2012; published online: 22 August 2012.

Citation: Cosgrove DJ and Jarvis MC (2012) Comparative structure and biomechanics of plant primary and secondary cell walls. Front. Plant Sci. 3:204. doi: 10.3389/fpls.2012.00204

This article was submitted to Frontiers in Plant Physiology, a specialty of Frontiers in Plant Science.

Copyright (c) 2012 Cosgrove and Jarvis. This is an open-access article distributed under the terms of the Creative Commons Attribution License, which permits use, distribution and reproduction in other forums, provided the original authors and source are credited and subject to any copyright notices concerning any third-party graphics etc. 